\title{
Electrochemical Detection of Ivermectin Used for the Treatment of COVID-19 with Glutardialdehyde-Modified Glassy Carbon Electrode
}

\author{
Berna Koçak ${ }^{1,2}$ (1) Yeliz İpek ${ }^{1,2}$ (1)
}

Accepted: 24 December 2021 / Published online: 5 January 2022

(c) The Author(s), under exclusive licence to Springer Science+Business Media, LLC, part of Springer Nature 2022

\begin{abstract}
In this study, the surface of the glassy carbon electrode was modified with glutardialdehyde. The modified glassy carbon electrode showed electrocatalytic activity against ivermectin. The glassy carbon electrode modified with glutardialdehyde showed high sensitivity, selectivity, and stability in the determination of ivermectin. The peak current of glutardialdehyde oxidation obtained by differential pulse voltammetry decreased inversely with the ivermectin concentration. Ivermectin inhibited the oxidation reaction of glutardialdehyde and caused a decrease in current. This change made the analysis of ivermectin electrochemically possible. In order to demonstrate the applicability of the developed method in real samples, recovery studies were carried out in tap water and urine. The highest sensitivity $\left(0.45 \mu \mathrm{A} /\left(\left(\mu \mathrm{mol} \cdot \mathrm{L}^{-1}\right)\left(\mathrm{cm}^{2}\right)\right)\right)$ was achieved with urine sample and the lowest detection limit as $2.66 \times 10^{-6} \mathrm{~mol} \cdot \mathrm{L}^{-1}$ was obtained with BRT solution sample.
\end{abstract}

Keywords Ivermectin · Voltammetry · Electrochemical sensor · Glutardialdehyde · COVID-19

\section{Introduction}

The COVID-19 outbreak first appeared in the city of Wuhan, in Hubei Province of China, in early December 2019, according to the World Health Organization (WHO). By spreading to Europe, the USA, and other continents, it has deeply affected international political and economic relations as well as the world's health system [1,2]. In order to prevent this disease, various vaccines have been developed and vaccination processes have started rapidly. In addition, various studies have been carried out on treatment methods for patients. COVID-19 is caused by the betacoronavirus that causes pneumonia by affecting the lower respiratory tract, called SARS-CoV-2 [3]. SARS-CoV-2 is considered as a relative of Middle East respiratory syndrome (MERS) and

Yeliz İpek

yelizipek@munzur.edu.tr

Berna Koçak

bernakocak@munzur.edu.tr

1 Department of Chemistry and Chemical Process Technologies, Vocational School of Tunceli, Munzur University, 62000 Tunceli, Turkey

2 Rare Earth Elements Research and Application Center, Munzur University, 62000 Tunceli, Turkey severe acute respiratory syndrome (SARS). The betacoronavirus is a positive single-stranded RNA virus [4].

Ivermectin (IVM) is a FDA-approved broad-spectrum anti-parasitic agent, and recent studies have demonstrated antiviral effects on many RNA and DNA viruses, including SARS-CoV-2 [2, 5-9]. Based on drug safety sheet data for ivermectin (New Drug Application Identifier: 50-742/S022), possible side effects are as follows: increase in alanine aminotransferase and aspartate aminotransferase (2\%), headache (6\%), dysmenorrhea (5.5\%), leukocyte count decrease (3\%), dizziness (3\%), itching (3\%), peripheral edema (3\%), tachycardia (3\%), nausea (2\%), upper respiratory tract infection symptoms (1.8\%), and diarrhea (1.8\%) [10].

In addition, ivermectin, which is frequently used by cattle breeders due to its effectiveness against parasites, can accumulate in fat and muscle tissue over time due to its lipophilicity [11]. When meat obtained from cattle is consumed by humans, it is important to analyze the accumulation of ivermectin in its structure. If the ivermectin concentration in beef is higher than the maximum allowable residue limit $\left(100 \mu \mathrm{g} \cdot \mathrm{kg}^{-1}\right)$, the beef is considered as contaminated and may cause embryotoxicity [12].

Various studies have been conducted on residue analyzes of ivermectin in blood plasma [13, 14] and urine [15]. For the determination of IVM, liquid chromatography-tandem 
mass spectrometry [14, 16-22], high-performance liquid chromatography [23-26], and amperometric methods [27] were used. Difficulties in implementation of the chromatographic methods, such as need for specialists, need for expensive devices, high solvent consumption, and the complex preprocessing treatments, made electrochemical sensor applications more attractive.

In this study, the electrochemical analysis methods which are more cost-effective, have low sensitivity, and have less solvent consumption were applied for detection of IVM residual in BRT buffer solution, in tap water, and in urine sample. Glutaraldehyde or glutardialdehyde is used as a cross-linker for electrode modification in electrochemical sensor studies [28-30] and allows the sensor material to be immobilized to the electrode surface. İpek [31] used glutaraldehyde as a sensing element for the analysis of carbaryl pesticide. Glassy carbon electrode (GCE) was modified with glutardialdehyde and $\mathrm{GA}_{2} / \mathrm{GCE}$ electrode was achieved for IVM detection.

\section{Materials and Method}

\section{Chemicals}

Electrochemical studies were performed with the Ivium pocketstat potentiostat/galvanostat impedance analyzer. During the experimental studies, ultrapure water from the Millipore direct-3QV brand device was used. $\mathrm{pH}$ measurements were carried out with the Ohaus starter 3000 Bench $\mathrm{pH}$ meter. In voltammetric studies, glassy carbon electrode (GCE, CHI104) and GCE modified with glutardialdehyde electrode $\left(\mathrm{GA}_{2} / \mathrm{GCE}\right)$ were used as working electrodes in separate measurements. $\mathrm{Ag} / \mathrm{AgCI}\left(3 \mathrm{~mol} \cdot \mathrm{L}^{-1} \mathrm{NaCI}\right)$ electrode was utilized as reference electrode (MF-2052, BASI) and as counter electrode $\mathrm{Pt}$ wire was used. Ivermectin (IVM, CAS no: 70288-86-7) determined during the study was obtained from Sigma-Aldrich company. The stock solution of $1 \times 10^{-3} \mathrm{~mol} \cdot \mathrm{L}^{-1}$ IVM was prepared in methanol and stored at $+4{ }^{\circ} \mathrm{C}$. Glutardialdehyde $\left(\mathrm{GA}_{2}, 25 \%\right)$ which was used in the modification of the electrode surface was obtained from Merck company. In addition, all chemicals (sodium hydroxide $(\mathrm{NaOH})$, hydrochloric acid $(\mathrm{HCl})$, boric acid $\left(\mathrm{H}_{3} \mathrm{BO}_{3}\right)$, acetic acid $\left(\mathrm{CH}_{3} \mathrm{COOH}\right)$, and phosphoric acid $\left.\left(\mathrm{H}_{3} \mathrm{PO}_{4}\right)\right)$ which were used for the Britton-Robinson buffer (BRT) solution preparation were of analytical purity and were obtained from Merck company.

\section{Preparation of $\mathrm{GA}_{\mathbf{2}} / \mathrm{GCE}$ Electrode}

The surface of the GCE was cleaned and polished using aluminum oxide (alumina, $\mathrm{Al}_{2} \mathrm{O}_{3}$ ) with $0.05 \mu \mathrm{m}$ particle size. Glassy carbon electrode was sonicated in an ultrasonic bath in deionized water for $10 \mathrm{~min}$ in order to clean the alumina residues remaining on its surface. $\mathrm{GA}_{2} / \mathrm{GCE}$ electrode was obtained as a result of dropping $5.0 \mu \mathrm{L}$ of $5 \%$ glutardialdehyde $\left(\mathrm{GA}_{2}\right)$ solution onto the cleaned electrode surface and drying it at room temperature and conditions for $2 \mathrm{~h}$.

\section{Ivermectin Analysis}

Glassy carbon electrode modified with $\mathrm{GA}_{2}\left(\mathrm{GA}_{2} / \mathrm{GCE}\right)$ was used as the working electrode. In order to increase the solubility of ivermectin, methanol was added to the solution medium at $25 \%$ of the volume of the buffer solution. Before adding ivermectin to the phosphate buffer, differential pulse voltammograms of the buffer were recorded. Then, voltammetric measurements were made by adding ivermectin with known concentration to the electrolytic buffer solution. The optimized operating conditions for differential pulse voltammetry (DPV) measurements of ivermectin are as follows: $\mathrm{pH}$ value of 12.02 for phosphate buffer as supporting electrolyte, pulse time: $10 \mathrm{~ms}$, pulse amplitude: $200 \mathrm{mV}$, scan rate: $50 \mathrm{mV} \mathrm{s}^{-1}$, and Estep: $2 \mathrm{mV}$.

\section{Results and Discussion}

\section{Electrode Characterization}

Modified electrode surface was investigated with a stereo microscope equipped with Sony IMX485 sensor, coaxial lamp, and Nikon monocular C-Mount lens. The achieved optical images were given in Fig. 1.

A homogenous, uniform thin film with a thickness about $40 \mu \mathrm{m}$ was observed with the microscope. After preparation of modified electrode, electrochemical measurements were applied with differential pulse voltammetry (DPV) technique. DPV images of GCE and modified $\mathrm{GA}_{2} / \mathrm{GCE}$ electrode were exhibited in Fig. 2.

After a smooth and clean DPV voltammogram had been achieved with GCE electrode, it was modified with $\mathrm{GA}_{2}$. $\mathrm{GA}_{2} / \mathrm{GCE}$ electrode had two oxidation peaks at $0.9 \mathrm{~V}$ and $1.45 \mathrm{~V}$ as $\mathrm{O} 1$ and $\mathrm{O} 2$ peaks, respectively.

\section{Determination of Working pH}

Anodic behavior of $2.85 \times 10^{-4} \mathrm{~mol} \cdot \mathrm{L}^{-1}$ ivermectin in BRT solution at different $\mathrm{pH}$ values $(\mathrm{pH} 1.99, \mathrm{pH} 5.01, \mathrm{pH} 7.02$, $\mathrm{pH}$ 9.01, $\mathrm{pH}$ 11.02, $\mathrm{pH}$ 12.02) was investigated with GCE and DPV technique. The highest anodic peak current was obtained at pH 12.02, as shown in Fig. 3. Thus, pH 12.02 BRT buffer solution was used throughout the electrochemical detection studies.

Figure 3(a) shows the change in the current value of the ivermectin peak detected using GCE with the change in the 

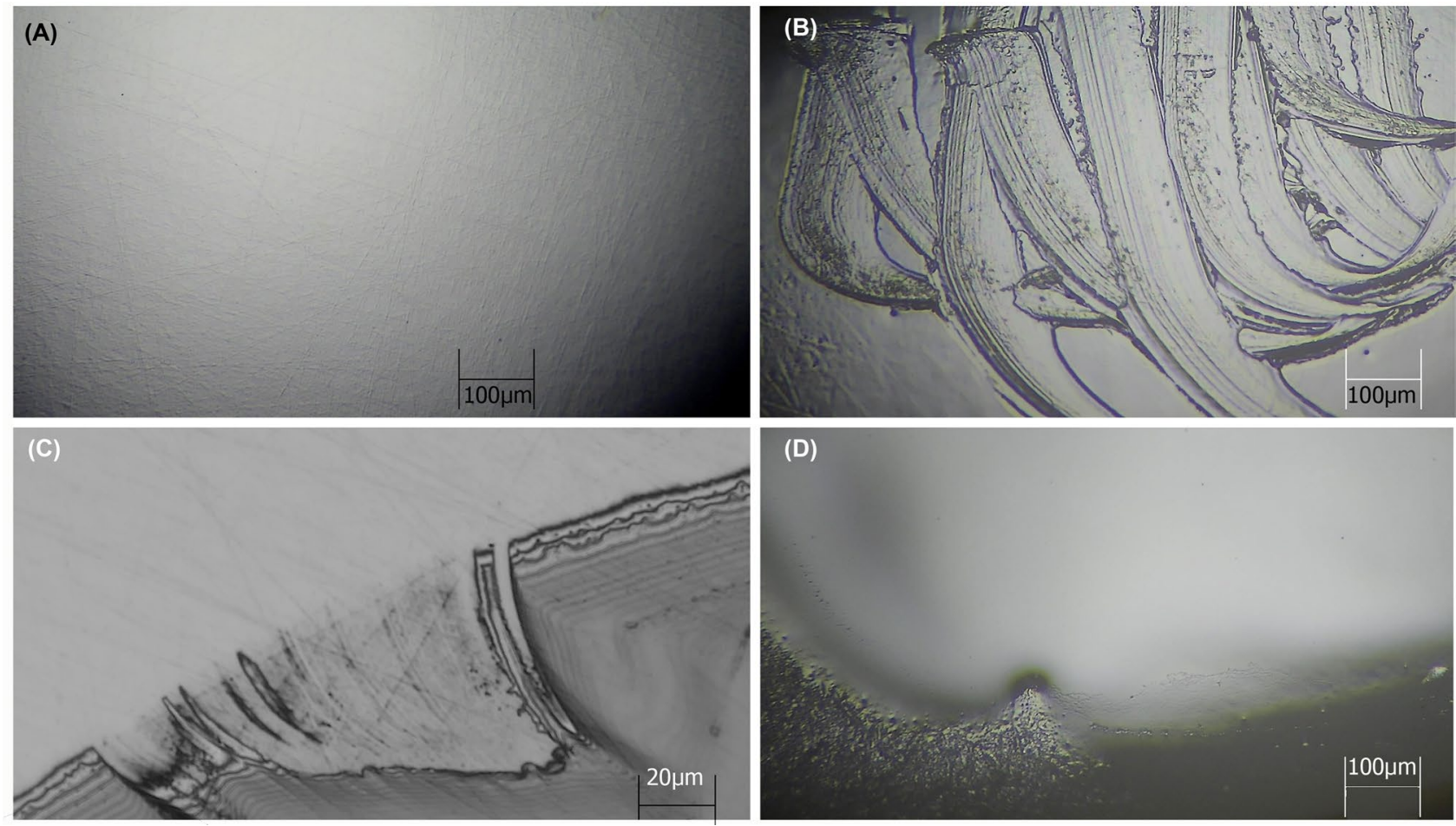

Fig. $1 \mathrm{GA}_{2} / \mathrm{GCE}$-modified electrode (A) $\mathrm{GA}_{2}$ film surface, (B) scratched $\mathrm{GA}_{2}$ film, (C) film cross-section, (D) film edge

hydrogen concentration of the medium. Accordingly, $\mathrm{pH} 9$ was a critical value, and an increasing trend in the peak current was observed after $\mathrm{pH}$ 9. The maximum peak current was obtained when the $\mathrm{pH}$ value of the BRT solution used was 12.02. In Fig. 3(b), the changes in the peak potential simultaneously with the peak current changes are shown.
The breaking point at the peak potential was observed at $\mathrm{pH}$ 7.02. While the peak potential decreased up to $\mathrm{pH} 7.02$, the potential value increased after $\mathrm{pH}$ 7.02. Since the high peak current will allow the sensor to make more sensitive measurements, the $\mathrm{pH}$ was chosen as 12.02 for the electrochemical ivermectin sensor studies.
Fig. 2 DPV voltammograms of GCE and $\mathrm{GA}_{2} / \mathrm{GCE}$ electrodes in BRT solution

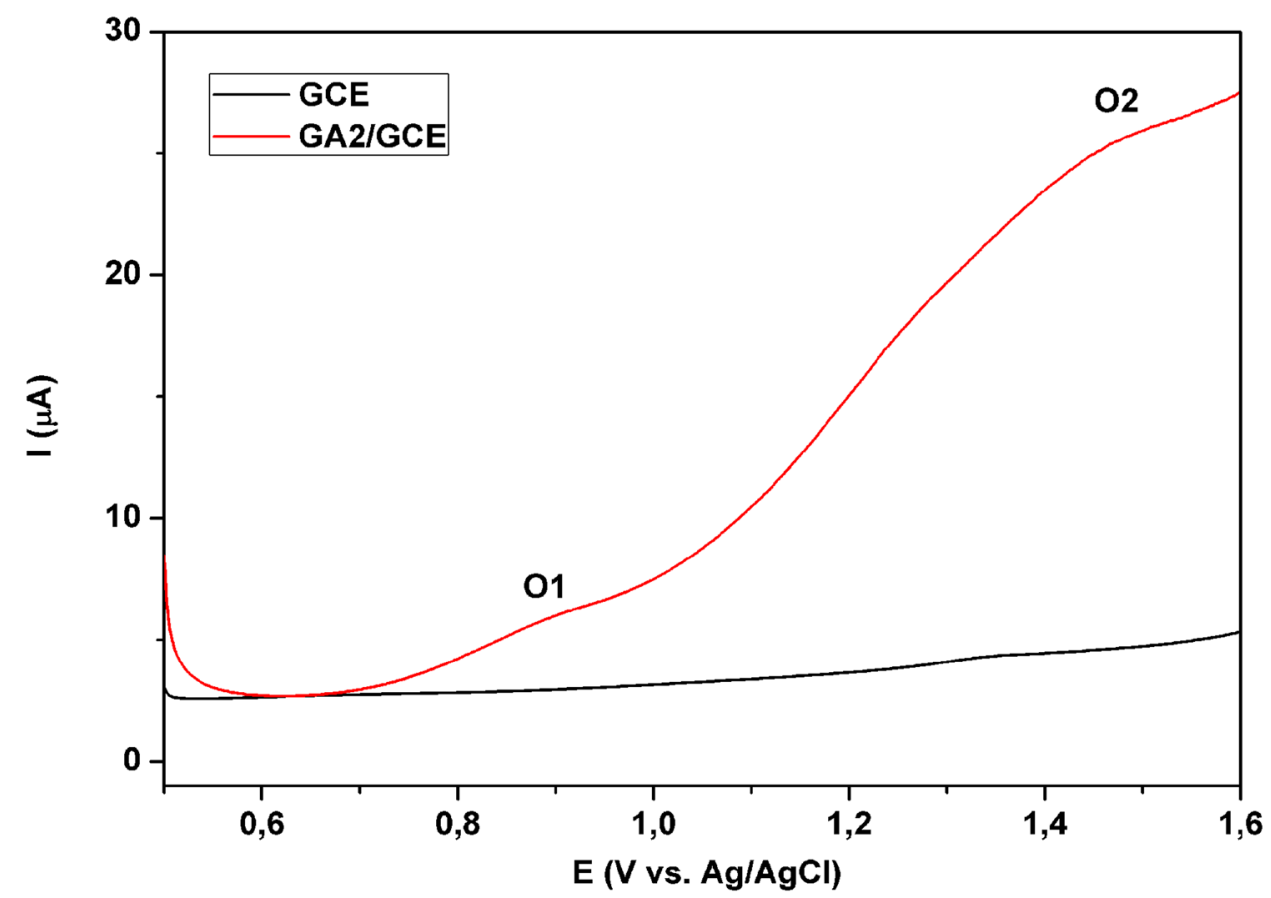



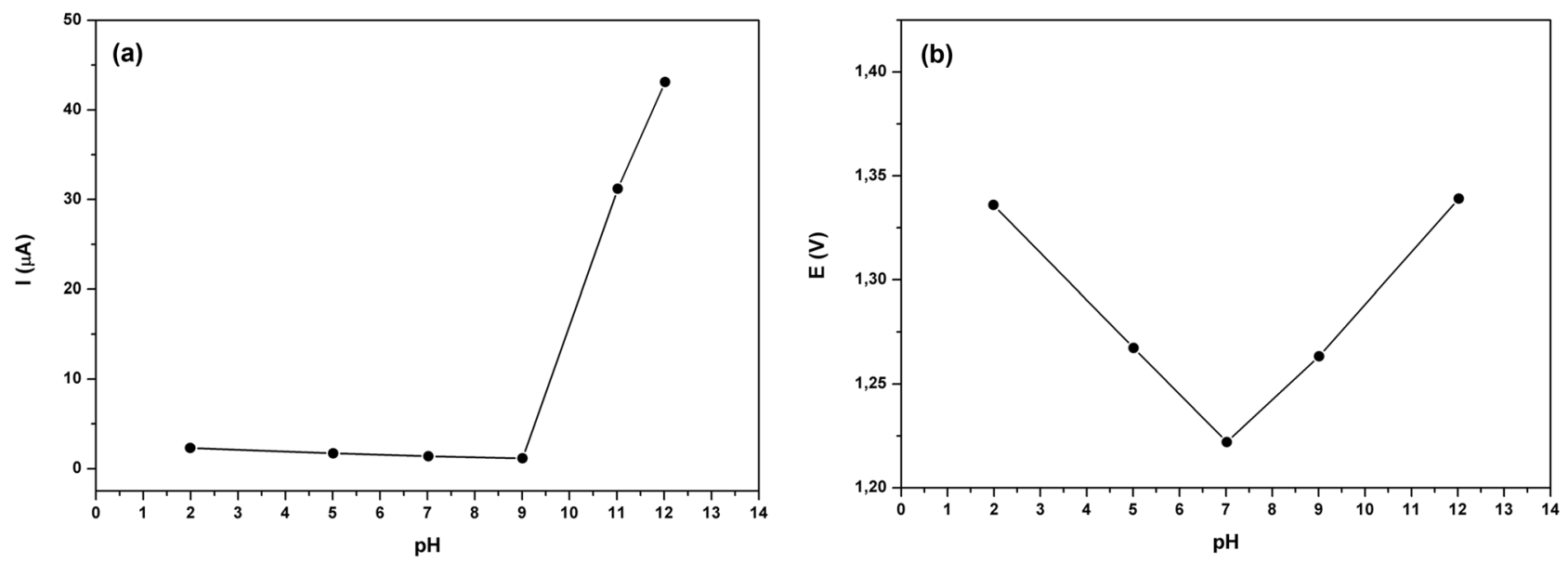

Fig. 3 Effect of $\mathrm{pH}$ on the peak current intensity of $2.85 \times 10^{-4} \mathrm{~mol} \cdot \mathrm{L}^{-1}$ ivermectin: (a) peak current vs. $\mathrm{pH}$ and (b) peak potential vs. $\mathrm{pH}$

\section{Detection of IVM with $\mathrm{GA}_{2} / \mathrm{GCE}$ Electrode in BRT Solution}

Electrochemical behaviors of $2.85 \times 10^{-4} \mathrm{~mol} \cdot \mathrm{L}^{-1}$ ivermectin were investigated using GCE and $\mathrm{GA}_{2} / \mathrm{GCE}$ electrodes separately using DPV technique. The resulting DPV voltammograms are shown in Fig. 4. The peak current obtained with the $\mathrm{GA}_{2} / \mathrm{GCE}$ electrode was sharper and more pronounced than the peak current obtained with the GCE electrode, and its intensity was 1.46 times higher. This result showed that the $\mathrm{GA}_{2} / \mathrm{GCE}$-modified electrode was more sensitive to IVM.
DPV is preferred more than CV because of its sensitivity and low background current [32]. Quantitative determination of IVM was applied using the DPV method and $\mathrm{GA}_{2} / \mathrm{GCE}$ modified electrode in BRT solution at $\mathrm{pH}$ 12.02. The DPV voltammograms and calibration curve was given in Fig. 5.

DPV measurements started with $0.99 \mu \mathrm{mol} \cdot \mathrm{L}^{-1}$ concentration of IVM and gradually IVM concentration increased until reaching $444 \mu \mathrm{mol} \cdot \mathrm{L}^{-1}$ concentration. Ten repetitive measurements were applied for each concentration of IVM in BRT solution at $\mathrm{pH}$ 12.02. The standard deviation of the results were calculated with these repetitive measurements. The peak potential was $1.286 \mathrm{~V}$ and the
Fig. 4 Differential pulse voltammograms for glassy carbon electrode and $\mathrm{GA}_{2} / \mathrm{GCE}$ electrode in BRT ( $\mathrm{pH}$ 12.02) solution in the presence of $2.85 \times 10^{-4} \mathrm{~mol} \cdot \mathrm{L}^{-1} \mathrm{IVM}$

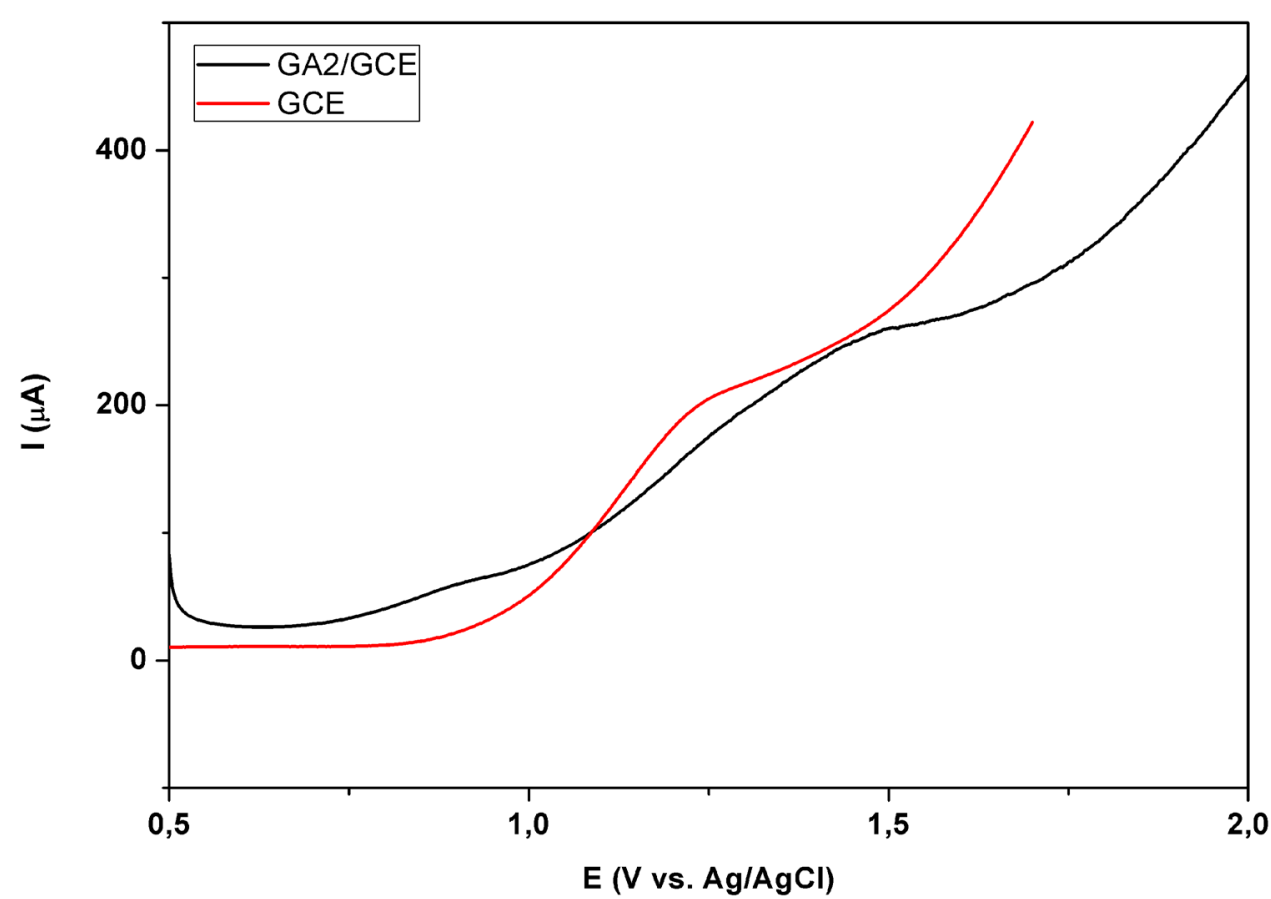


Fig. 5 Electrochemical quantitative detection of IVM with $\mathrm{GA}_{2} /$ GCE electrode in BRT solution at $\mathrm{pH}$ 12.02; (a) DPV technique voltammograms of different IVM concentrations and (b) peak current intensities of each concentration of IVM (calibration curve)

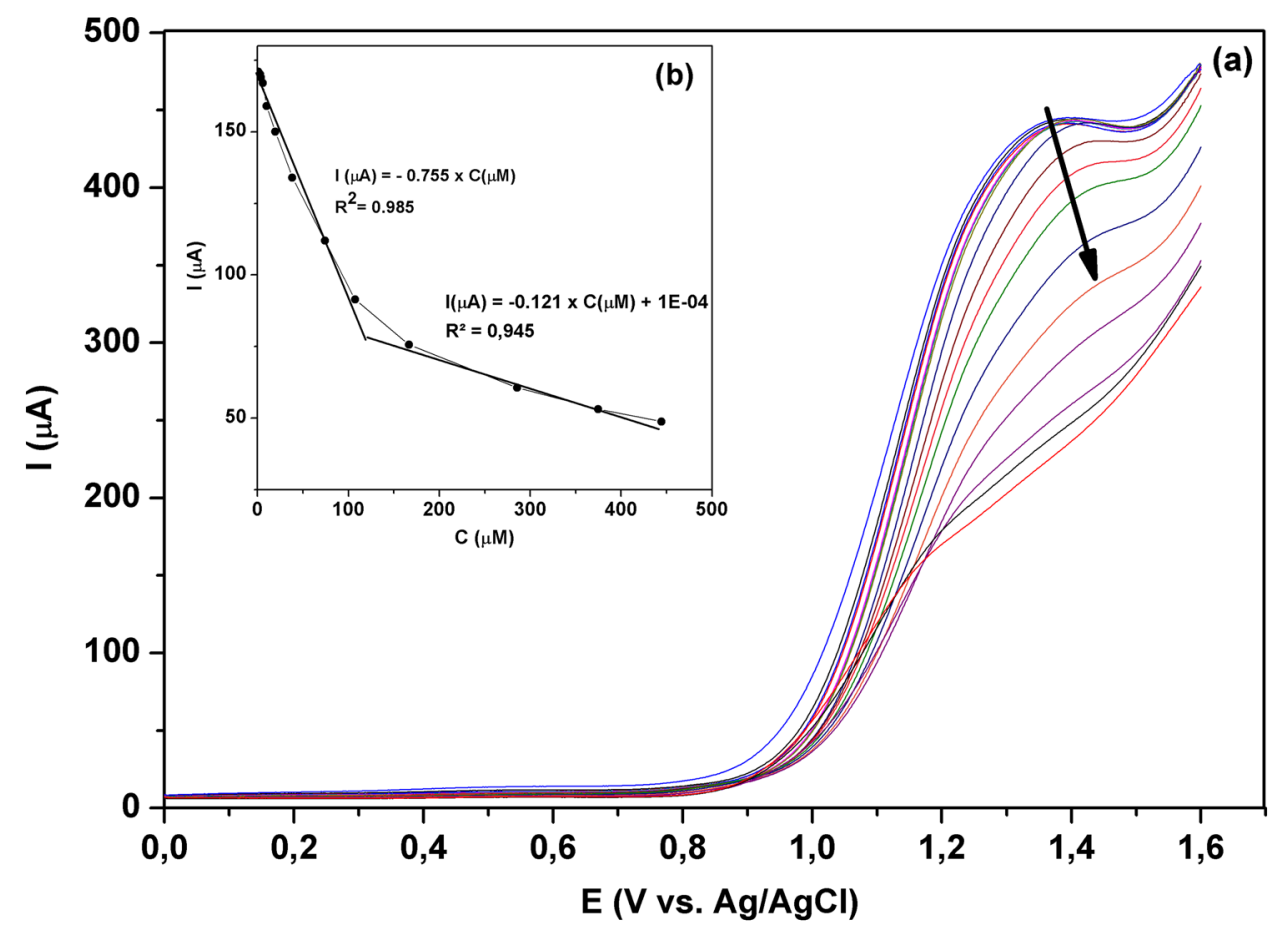

current intensity decreased with addition of IVM into solution. The oxidation peak was thought to be corresponding with glutardialdehyde and addition of IVM inhibited the oxidation activity of glutardialdehyde. The inhibition leads the decrease in the peak current intensity as given in Fig. 5a, b. To see this decrease and calculate the sensor properties, peak current intensities plotted against each concentration of IVM and exhibited in the inner graph as Fig. 5(b).

There was two linear concentration ranges. In the linear concentration, ranges were between $9.99 \times 10^{-7} \mathrm{~mol} \cdot \mathrm{L}^{-1}-1$. $1 \times 10^{-4} \mathrm{~mol} \cdot \mathrm{L}^{-1}$ and $1.1 \times 10^{-4} \mathrm{~mol} \cdot \mathrm{L}^{-1}-4.41 \times 10^{-4} \mathrm{~mol} \cdot \mathrm{L}^{-}$ 1 , respectively. In both ranges, the peak current intensity of the IVM decreased linearly. Linear regression equation for the 1 st operating range was $I(\mu \mathrm{A})=-0.755 \mathrm{C}\left(\mu \mathrm{mol} \cdot \mathrm{L}^{-1}\right)$ with a regression coefficient of $R^{2}=0.985$. Linear regression equation for 2 nd working range was $I(\mu \mathrm{A})=-0.121 \mathrm{C}$ $\left(\mu \mathrm{mol} \cdot \mathrm{L}^{-1}\right)+1 \times 10^{-4}$ having the regression coefficient of $R^{2}=0.985$. The limit of detection $(L O D)$ value of the modified electrode can be calculated using Eq. 1 [33]:

$L O D=\frac{3 S}{m}$

In this equation, $S$ is standard deviation of the measurements and $m$ is the slope of the calibration line in the linear range. $L O D$ was calculated to be $2.66 \times 10^{-6} \mathrm{~mol} \cdot \mathrm{L}^{-1}$ for the first linear range and $3.89 \times 10^{-5} \mathrm{~mol} \cdot \mathrm{L}^{-1}$ for the second linear range. Limit of quantitation $(L O Q)$ value can be calculated using Eq. 2 [33]:

$L O Q=\frac{10 S}{m}$
Table 1 Analytical parameters for the voltammetric determination of IVM by differential pulse voltammetry (DPV) in BRT (pH 12.02) solution, using $\mathrm{GA}_{2} / \mathrm{GCE}$ electrode

\begin{tabular}{lll}
\hline Method (DPV) & 1 st linear range & 2nd linear range \\
\hline Linear working range, mol L & $9.99 \times 10^{-7}-1.1 \times 10^{-4}$ & $1.1 \times 10^{-4}-4.41 \times 10^{-4}$ \\
Slope, $\mathrm{A} / \mathrm{mol} \mathrm{L}^{-1}$ & -0.755 & -0.123 \\
Regression coefficient, $R^{2}$ & 0.985 & 0.945 \\
$L O D, \mathrm{~mol} \mathrm{~L}^{-1}$ & $2.66 \times 10^{-6}$ & $3.89 \times 10^{-5}$ \\
$L O Q, \mathrm{~mol} \mathrm{~L}^{-1}$ & $8.87 \times 10^{-6}$ & $1.30 \times 10^{-4}$ \\
Repeatability of peak potential, $\mathrm{RSD}^{\mathrm{a} \% \text { (intra-day) }}$ & 0.94 & \\
Repeatability of peak potential, $\mathrm{RSD}^{\mathrm{a}}$ (intra-day) & 0.50 & \\
Repeatability of peak current, $\mathrm{RSD}^{\mathrm{a}}$ (intra-day) & 0.82 & \\
Repeatability of peak current, $\mathrm{RSD}^{\mathrm{a}} \%$ (intra-day) & 1.12 & \\
\hline
\end{tabular}

Relative standard deviation, $\mathrm{RSD} \%=(\mathrm{s} \div x),{ }^{\mathrm{a}} n=3$ 
Fig. 6 Electrochemical quantitative detection of IVM with $\mathrm{GA}_{2} /$ GCE electrode in (BRT solution + tap water) solution at $\mathrm{pH}$ 12.02; (a) DPV voltammograms of different IVM concentrations and (b) peak current intensities of each concentration of IVM (calibration curve)

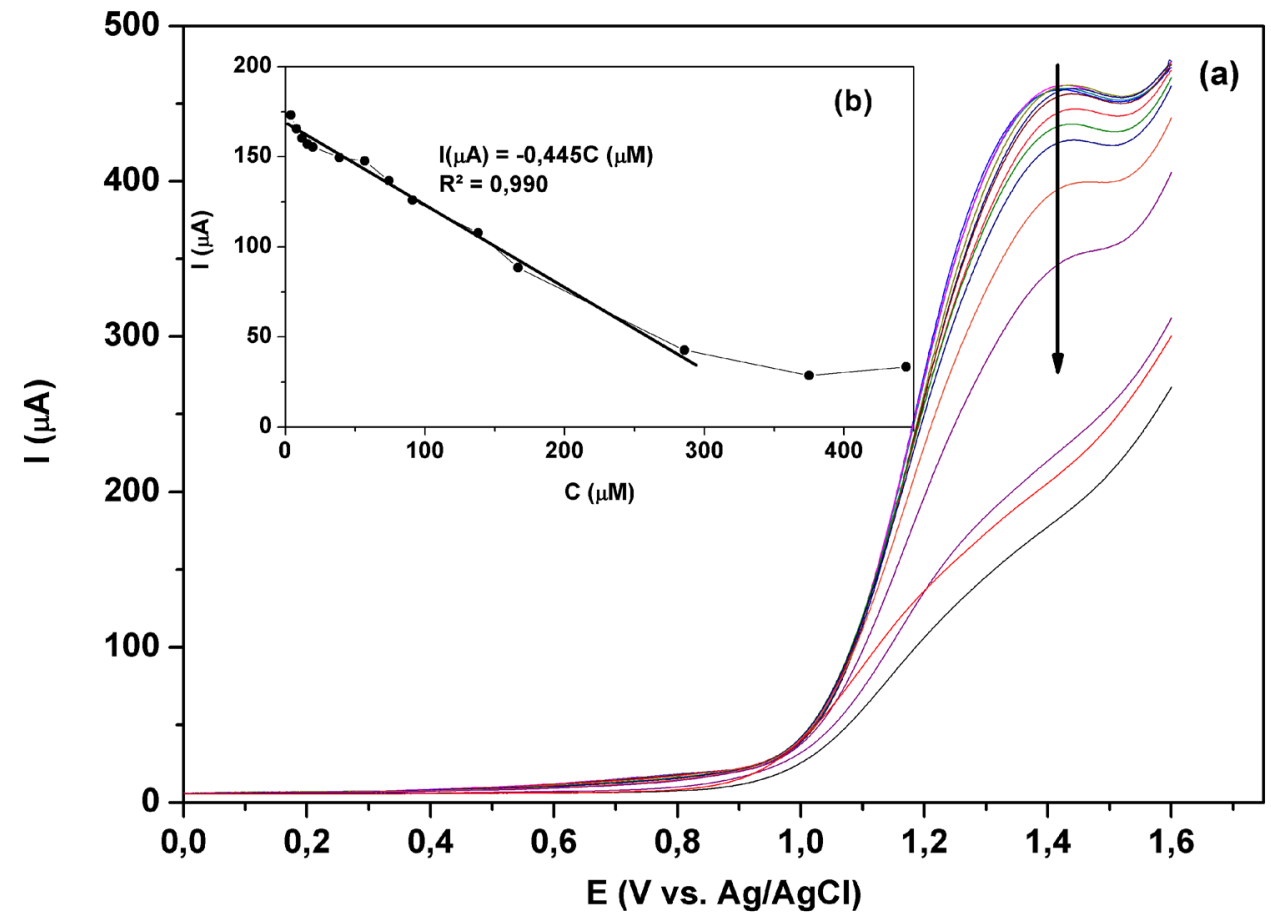

$L O Q$ was found to be $8.87 \times 10^{-6} \mathrm{~mol} \cdot \mathrm{L}^{-1}$ for the first linear range and $1.30 \times 10^{-4} \mathrm{~mol} \cdot \mathrm{L}^{-1}$ for the second linear range. The sensor parameters of $\mathrm{GA}_{2} / \mathrm{GCE}$ electrode for IVM detection were given in Table 1.

This proposed method for the determination of IVM was carried out in a shorter time than the previous chromatographic and electrochemical methods and at an affordable cost without any synthesis or pre-separation process [15, 23, 27, 34].

In order to determine the measurement repeatability of $\mathrm{GA}_{2} / \mathrm{GCE}, 3$ separate measurements of $0.285 \mathrm{mM}$ IVM were taken during the day with the same electrode. The relative standard deviation (RSD\%) of this electrode was calculated as 0.82 . To estimate the reproducibility of $\mathrm{GA}_{2} / \mathrm{GCE}$, the relative standard deviations (RSD\%) of the three independently prepared electrodes using solution containing $0.285 \mathrm{mmol} \cdot \mathrm{L}^{-1}$ IVM were calculated as 1.12. These results showed that the measurement repeatability and reproducibility of the developed modified electrode were at desirable level.

\section{Sensor Studies of IVM Residue in Tap Water Sample}

Increasing amount of $1 \times 10^{-3} \mathrm{~mol} \cdot \mathrm{L}^{-1} \mathrm{IVM}$ solution was added into the electrolytic BRT solution and tap water. Tap water was $25 \%$ by volume of the total solution. The electrochemical activity against the $\mathrm{GA}_{2}$ /GCE electrode was measured and the DPV data were recorded (Fig. 6(a)). A linear calibration plot was drawn using peak current intensities of the voltammograms (Fig. 6(b)). An excellent linearity was found between $3.98 \times 10^{-6} \mathrm{~mol} \cdot \mathrm{L}^{-1}$ and $2.85 \times 10^{-4} \mathrm{~mol} \cdot \mathrm{L}^{-1}$. The linear regression equation was calculated as $I(\mu \mathrm{A})=-0.445 \mathrm{C}\left(\mu \mathrm{mol} \cdot \mathrm{L}^{-1}\right)$ and the regression coefficient was $R^{2}=0.990 . L O D$ and $L O Q$ values were calculated as $1.54 \times 10^{-5} \mathrm{~mol} \cdot \mathrm{L}^{-1}$ and $5.13 \times 10^{-5} \mathrm{~mol} \cdot \mathrm{L}^{-1}$, respectively.

In order to determine the feasibility of this method, recovery studies were carried out with tap water sample. Achieved data were shown in Table 2.

\section{Sensor Studies of IVM Residue in Urine Sample}

Canga et al. [5] reported in their review article that only $1 \%$ of ivermectin and its metabolites were removed via urine from the body. The urine sample taken from a healthy individual was added to the BRT (pH 12.02) solution, constituting $25 \%$ of the total electrolytic solution by volume, and the stock IVM solution $\left(1 \times 10^{-3} \mathrm{~mol} \cdot \mathrm{L}^{-1}\right)$ was gradually added to the resulting electrolyte solution and the DPV

Table 2 Determination and recovery $\%$ of IVM in tap water (number of experiments; $n=3$ )

\begin{tabular}{lll}
\hline IVM added $(\mathrm{mg})$ & Found $(\mathrm{mg})$ & Recovery $(\%)$ \\
\hline 0.7 & 0.726638 & 103.7935 \\
0.7 & 0.706752 & 100.953 \\
0.7 & 0.736984 & 105.2713 \\
\hline
\end{tabular}

These results showed that the method for the determination of IVM with $\mathrm{GA}_{2} / \mathrm{GCE}$ can also be applied to real samples. 
Fig. 7 Electrochemical quantitative detection of IVM with $\mathrm{GA}_{2} / \mathrm{GCE}$ electrode in (BRT solution + urine) solution at $\mathrm{pH}$ 12.02; (a) DPV voltammograms of different IVM concentrations and (b) peak current intensities of each concentration of IVM (calibration curve)

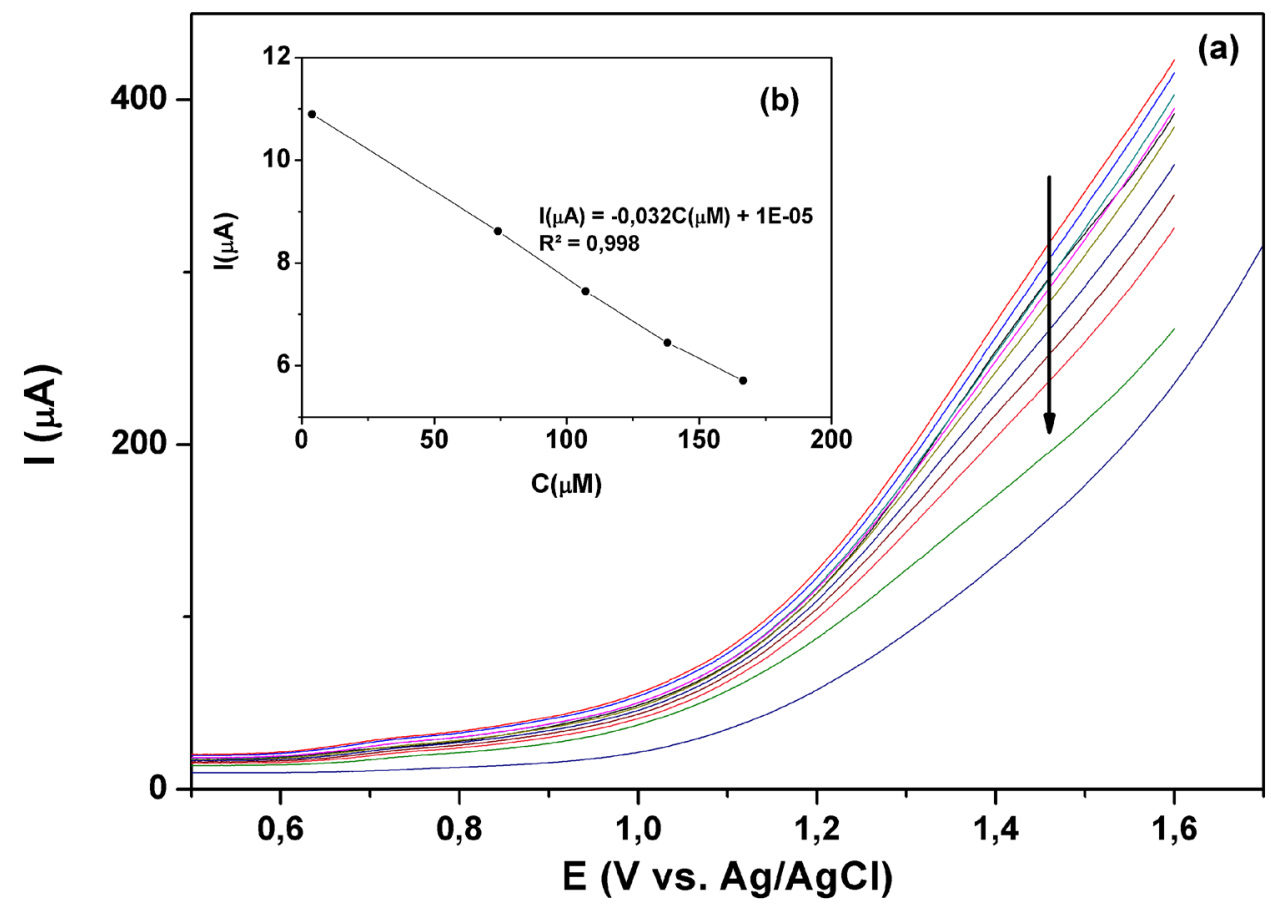

Table 3 Determination and recovery $\%$ of IVM in urine (number of experiments; $n=3$ )

\begin{tabular}{lll}
\hline IVM added $(\mathrm{mg})$ & Found $(\mathrm{mg})$ & Recovery $(\%)$ \\
\hline 0.0875 & 0.0540 & 61.76066 \\
0.0875 & 0.0552 & 63.11841 \\
0.0875 & 0.0522 & 59.74093 \\
\hline
\end{tabular}

data were recorded (Fig. 7(a)). A linear calibration plot was drawn using the recorded voltammograms (Fig. 7(b)) and an excellent linearity was found between $3.98 \times 10^{-6} \mathrm{~mol} \cdot \mathrm{L}^{-1}$ and $1.667 \times 10^{-4} \mathrm{~mol} \cdot \mathrm{L}^{-1}$. The linear equation of the calibration line was calculated as $I(\mu \mathrm{A})=-0.032 \mathrm{C}$ $\left(\mu \mathrm{mol} \cdot \mathrm{L}^{-1}\right)+1.0 \times 10^{-5}$ and the regression coefficient of calibration line was $R^{2}=0.998$. The $L O D$ and $L O Q$ values were calculated as $1.94 \times 10^{-5} \mathrm{~mol} \cdot \mathrm{L}^{-1}$ and $6.46 \times 10^{-5} \mathrm{~mol} \cdot \mathrm{L}^{-1}$, respectively.

Recovery calculations were made to show the applicability of this method. Recovery rates were shown in Table 3.

As a summary, $L O D, L O Q$, linear detection ranges, and sensitivity parameters of $\mathrm{GA}_{2}$ /GCE-modified electrode were given in Table 4 . While the highest sensitivity $(0.45 \mu \mathrm{A} /$ $\left.\left(\left(\mu \mathrm{mol} \cdot \mathrm{L}^{-1}\right)\left(\mathrm{cm}^{2}\right)\right)\right)$ was achieved with urine sample, the lowest detection limit as $2.66 \times 10^{-6} \mathrm{~mol} \cdot \mathrm{L}^{-1}$ was obtained with BRT solution sample. Since it has a high sensitivity in urine sample that consists of different materials having interference effect, it can be concluded that the selectivity of the electrode was in desired level. Excellent selectivity and sensitivity properties of $\mathrm{GA}_{2} / \mathrm{GCE}$-modified electrode make it a simple and low-cost sensor of IVM for water and urine samples.

Table 4 Sensor parameter of $\mathrm{GA}_{2} / \mathrm{GCE}$ for IVM determination in different samples

\begin{tabular}{|c|c|c|c|c|c|c|c|c|c|}
\hline \multirow[t]{2}{*}{ Sample } & \multicolumn{2}{|c|}{$L O D\left[\mathrm{~mol} \cdot \mathrm{L}^{-1}\right]$} & \multicolumn{2}{|c|}{$L O Q\left[\mathrm{~mol} \cdot \mathrm{L}^{-1}\right]$} & \multicolumn{2}{|l|}{ Linear range $\left[\mathrm{mol} \cdot \mathrm{L}^{-1}\right]$} & \multicolumn{2}{|c|}{$\begin{array}{l}\text { Sensitivity }[\mu \mathrm{A} / \\
\left(\left(\mu \mathrm{mol} \cdot \mathrm{L}^{-1}\right)\right. \\
\left.\left.\left(\mathrm{cm}^{2}\right)\right)\right] \\
\end{array}$} & \multirow[t]{2}{*}{ Recovery $\%$} \\
\hline & LR1 & LR2 & LR1 & LR2 & LR1 & LR2 & LR1 & LR2 & \\
\hline BRT solution & $2.66 \times 10^{-6}$ & $3.89 \times 10^{-5}$ & $8.87 \times 10^{-6}$ & $1.30 \times 10^{-4}$ & $9.99 \times 10^{-7}-1.1 \times 10^{-4}$ & $1.1 \times 10^{-4}-4.41 \times 10^{-4}$ & 10.69 & 1.71 & 100 \\
\hline $\begin{array}{l}\text { BRT solu- } \\
\text { tion + tap } \\
\text { water }\end{array}$ & $1.54 \times 10^{-5}$ & - & $5.13 \times 10^{-5}$ & - & $3.98 \times 10^{-6}-2.85 \times 10^{-4}$ & - & 6.30 & - & 103.34 \\
\hline $\begin{array}{l}\text { BRT solu- } \\
\text { tion + urine }\end{array}$ & $1.94 \times 10^{-5}$ & - & $6.46 \times 10^{-5}$ & - & $3.98 \times 10^{-6}-1.667 \times 10^{-4}$ & - & 0.45 & - & 61.54 \\
\hline
\end{tabular}

$L R$, linear range. 


\section{Conclusions}

In this study, $\mathrm{GA}_{2} / \mathrm{GCE}$-modified electrode was used for the determination of IVM. Compared with GCE and $\mathrm{GA}_{2} / \mathrm{GCE}$, the higher peak current of IVM in the modified electrode showed that the modified electrode was more suitable for detection. The value of this study is that the electrode surface is modified without the need for any synthesis process and it allows rapid, sensitive, and selective determination of IVM at low concentrations. The modified electrode showed both good repeatability and stability. With the proposed method, recovery studies were carried out on real samples (tap water and urine) using the direct calibration graph method. The highest sensitivity $\left(0.45 \mu \mathrm{A} /\left(\left(\mu \mathrm{mol} \cdot \mathrm{L}^{-1}\right)\left(\mathrm{cm}^{2}\right)\right)\right)$ was achieved with urine sample and the lowest detection limit as $2.66 \times 10^{-6} \mathrm{~mol} \cdot \mathrm{L}^{-1}$ was obtained with BRT solution sample. Although the $\mathrm{GA}_{2} / \mathrm{GCE}$ electrode sensitivity was high with urine sample, its recovery \% average was 61.54. The interference effect of the other metabolites consisted in the urine prevented detection with $100 \%$ recovery ratio. Thus, it can be said that the selectivity of the electrode was lower for urine sample.

In further studies, ivermectin analysis in milk sample can be studied. In a study by Ogbuokiri et al. [35], when a healthy mother used ivermectin at a dosage of $150 \mu \mathrm{g} / \mathrm{kg}$, ivermectin concentration in breast milk was measured as $14.1 \mathrm{ng} \cdot \mathrm{mL}^{-1}$ $6.5 \mathrm{~h}$ later. Therefore, it will help mothers who have to use the ivermectin for medical purposes to measure the ivermectin residue in breast milk rapidly, sensitively, and selectively to choose the appropriate time to feed their babies.

\section{References}

1. V.M. Corman, O. Landt, M. Kaiser, R. Molenkamp, A. Meijer, D.K.W. Chu, T. Bleicker, S. Brünink, J. Schneider, M.L. Schmidt, D.G.J.C. Mulders, B.L. Haagmans, B. van der Veer, S. van den Brink, L. Wijsman, G. Goderski, J.-L. Romette, Ellis Joanna, M. Zambon, M. Peiris, H. Goossens, C. Reusken, M.P.G. Koopmans, C. Drosten, Eurosurveillance 25(3), 2000045 (2020)

2. F. Heidary, R. Gharebaghi, J. Antibiot. 73(9), 593 (2020)

3. C. Sohrabi, Z. Alsafi, N. O'Neill, M. Khan, A. Kerwan, A. AlJabir, C. Iosifidis, R. Agha, Int. J. Surg. 76, 71 (2020)

4. Y. İpek, Ö. Ertekin, Detection Methods and Novel Sensor Studies for Corona Virus, Editor: İrkin Reyhan, Edition: 1, Chapter 18, ISBN:978625-7884-57-0 (Gece Kitaplı $\breve{g} 1$, Ankara), pp. 287-303 (2020)

5. A.G. Canga, A.M.S. Prieto, M.J.D. Liébana, N.F. Martínez, M.S. Vega, J.J.G. Vieitez, AAPS J. 10(1), 42 (2008)

6. L. Caly, J.D. Druce, M.G. Catton, D.A. Jans, K.M. Wagstaff, Antiviral Res. 104787 (2020)

7. N.J. Barrows, R.K. Campos, S.T. Powell et al., Cell Host Microbe 20, 259 (2016)
8. K.M. Wagstaff, H. Sivakumaran, S.M. Heaton, D. Harrich, D.A. Jans, Biochem J. 443, 851 (2012)

9. X. Wang, C. Lv, X. Ji, B. Wang, L. Qiu, Z. Yang, Virus Res. 263, $80(2019)$

10. J. Munoz, M.R. Ballester, R.M. Antonijoan, I. Gich, M. Rodríguez, E. Colli, S. Gold, A.J. Krolewiecki, PLoS Negl Trop Dis 12(1), e0006020 (2018). https://doi.org/10.1371/journal.pntd.0006020

11. M.F. Bassissi, M. Alvinerie, A. Lespine, Comp. Biochem. Physiol. C: Toxicol. Pharmacol. 138, 437 (2004)

12. H. Wang, Z. Wang, S. Liu, Z. Liu, Bull. Environ. Contam. Toxicol. 82, 395 (2009)

13. K. Na-Bangchang, V. Banmairuroi, South East Asian Journal of Tropical Medicine and Public. Health 37(5), 848 (2006)

14. D. Kitzman, S.Y. Wei, L. Fleckenstein, J Pharm Biomed Anal. 40(4), 1013 (2006). https://doi.org/10.1016/j.jpba.2005.08.026

15. M.H. Mahnashi, A.M. Mahmoud, S.A. Alkahtani, M.M. El-Wekil, Journal of Alloys and Compounds. 871, 159627 (2021)

16. J. Mi, R. Zhang, F. Wang, H. Xu, B. Ge, J. He, ... \& B. Quarantine, Physical Testing and Chemical Analysis (Part B: Chemical Analysis). 09, (2017)

17. D. Löffler, T.A. Ternes, J. Chromatogr. A 1021(1-2), 133 (2003)

18. K. Yoshii, A. Kaihara, Y. Tsumura, S. Ishimitsu, Y. Tonogai, J. Chromatogr. A 896(1-2), 75 (2000)

19. S. Croubels, S. De Baere, M. Cherlet, P. De Backer, J. Mass Spectrom. 37(8), 840 (2002)

20. J.X. Huang, D.H. Lu, K. Wan, F.H. Wang, Chin. Chem. Lett. 25(4), 635 (2014)

21. R. Sheridan, L. Desjardins, J. AOAC Int. 89(4), 1088 (2006)

22. E. Morbidelli, J. Rambaldi, L.R. Bitti, A. Zaghini, A. Barbarossa, MethodsX 5, 1503 (2018)

23. N.S. Rashed, S. Zayed, A. Abdelazeem, F. Fouad, Microchemical Journal 105069 (2020)

24. D. Jabber, R. Norian, M. Jalilvand, Medical Laboratory Journal 11(2), 16 (2017)

25. D.R. Krishna, U. Klotz, Arzneimittelforschung 43(5), 609 (1993)

26. P.C. Tway, Jr J.S. Wood, G.V. Downing, Journal of Agricultural and Food Chemistry 29(5), 1059 (1981)

27. B.C. Lourencao, R.A. Medeiros, S.S. Thomasi, A.G. Ferreira, R.C. Rocha-Filho, O. Fatibello-Filho, Sens. Actuators, B Chem. 222, 181 (2016)

28. Z. Wang, Y. Jia, Carbon 130, 758 (2018). https://doi.org/10.1016/j. carbon.2018.01.078

29. M. Hulupi, H. Haryadi, Materials Today: Proceedings 13(1), 199 (2019). https://doi.org/10.1016/j.matpr.2019.03.214

30. T.H.V. Kumar, A.K. Sundramoorthy, Anal. Chim. Acta 1074, 131 (2019). https://doi.org/10.1016/j.aca.2019.05.011

31. Y. İpek, J. Indian Chem. Soc. 97(A-11), 2218 (2020).

32. M.L. Yola, N. Atar, Microchem. J. 170, 106643 (2021). https:// doi.org/10.1016/j.microc.2021.106643

33. H.T. Purushothama, Y.A. Nayaka, M.M. Vinay, P. Manjunatha, R.O. Yathisha, K.V. Basavarajappa, Journal of Science: Advanced Materials and Devices 3(2), 161 (2018)

34. N.V.S.K. Devaka, V.M. Rao, Pharmaceutical Sciences 25(3), 254 (2019)

35. J.E. Ogbuokiri, B.C. Ozumba, O.P. Okonkwo, Eur. J. Clin. Pharmacol 46, 389 (1993)

Publisher's Note Springer Nature remains neutral with regard to jurisdictional claims in published maps and institutional affiliations. 